Chapter 13

\title{
Wearable Antennas for Medical Applications
}

\author{
Albert Sabban \\ Additional information is available at the end of the chapter \\ http://dx.doi.org/10.5772/54663
}

\section{Introduction}

Microstrip antennas are widely employed in communication system and seekers. Microstrip antennas posse's attractive features such as low profile, flexible, light weight, small volume and low production cost. In addition, the benefit of a compact low cost feed network is attained by integrating the RF frontend with the radiating elements on the same substrate. Microstrip antennas are widely presented in books and papers in the last decade [1-7]. However, the effect of human body on the electrical performance of wearable antennas at $434 \mathrm{MHz}$ is not presented [8-13]. RF transmission properties of human tissues have been investigated in several articles [8-9]. Several wearable antennas have been presented in the last decade [10-14]. A review of wearable and body mounted antennas designed and developed for various applications at different frequency bands over the last decade can be found in [10]. In [11] meander wearable antennas in close proximity of a human body are presented in the frequency range between $800 \mathrm{MHz}$ and $2700 \mathrm{MHz}$. In [12] a textile antenna performance in the vicinity of the human body is presented at $2.4 \mathrm{GHz}$. In [13] the effect of human body on wearable $100 \mathrm{MHz}$ portable radio antennas is studied. In [13] the authors concluded that wearable antennas need to be shorter by $15 \%$ to $25 \%$ from the antenna length in free-space. Measurement of the antenna gain in [13] shows that a wide dipole $(116 \times 10 \mathrm{~cm})$ has $-13 \mathrm{dBi}$ gain. The antennas presented in [10-13] were developed mostly for cellular applications. Requirements and the frequency range for medical applications are different from those for cellular applications

In this chapter, a new class of wideband compact wearable microstrip antennas for medical applications is presented. Numerical results with and without the presence of the human body are discussed. The antennas VSWR is better than $2: 1$ at $434 \mathrm{MHz}+5 \%$. The antenna beam width is around $100^{\circ}$. The antennas gain is around 0 to $4 \mathrm{dBi}$. The antenna resonant frequency is shifted by $5 \%$ if the air spacing between the antenna and the human body is increased from 0 $\mathrm{mm}$ to $5 \mathrm{~mm}$. 


\section{Dually polarized $434 \mathrm{MHz}$ printed antenna}

A new compact microstrip loaded dipole antennas has been designed to provide horizontal polarization. The antenna dimensions have been optimized to operate on the human body by employing Agilent Advanced Design System (ADS) software [16]. The antenna consists of two layers. The first layer consists of RO3035 $0.8 \mathrm{~mm}$ dielectric substrate. The second layer consists of RT-Duroid $58800.8 \mathrm{~mm}$ dielectric substrate. The substrate thickness determines the antenna bandwidth. However, thinner antennas are flexible. Thicker antennas have been designed with wider bandwidth. The printed slot antenna provides a vertical polarization. In several medical systems the required polarization may be vertical or horizontal. The proposed antenna is dually polarized. The printed dipole and the slot antenna provide dual orthogonal polarizations. The dimensions of the dual polarized antenna presented in Figure 1are $26 \times 6 \times 0.16 \mathrm{~cm}$. The antenna may be used as a wearable antenna on a human body. The antenna may be attached to the patient shirt, patient stomach, or in the back zone. The antenna has been analyzed by using Agilent ADS software. There is a good agreement between measured and computed results. The antenna bandwidth is around 10\% for VSWR better than 2:1. The antenna beam width is around $100^{\circ}$. The antenna gain is around $2 \mathrm{dBi}$. The computed $\mathrm{S}_{11}$ and $S_{22}$ parameters are presented in Figure 2. Figure 3 presents the antenna measured $S_{11}$ parameters. The computed radiation patterns are shown in Figure 4 . The co-polar radiation pattern belongs to the yz plane. The cross-polar radiation pattern belongs to the xz plane. The antenna cross polarized field strength may be adjusted by varying the slot feed location. The dimensions of the folded dually polarized antenna presented in Figure 5 are $7 \times 5 \times 0.16 \mathrm{~cm}$. Figure 6 presents the antenna computed $S_{11}$ and $S_{22}$ parameters. The computed radiation patterns of the folded dipole are shown in Figure 7. The antennas radiation characteristics on human body have been measured by using a phantom. The phantom electrical characteristics represent the human body electrical characteristics.

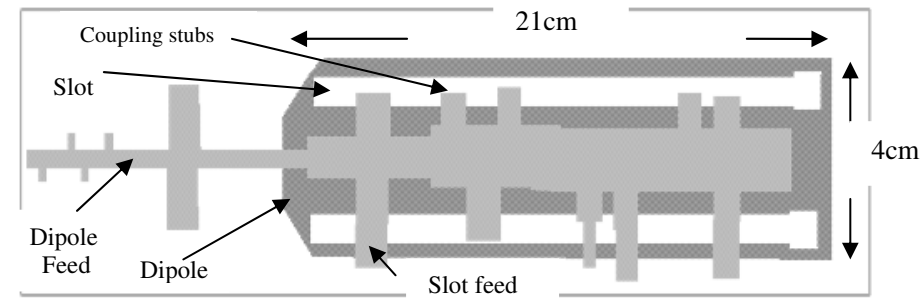

Figure 1. Printed dually polarized antenna, $26 \times 6 \times 0.16 \mathrm{~cm}$. 


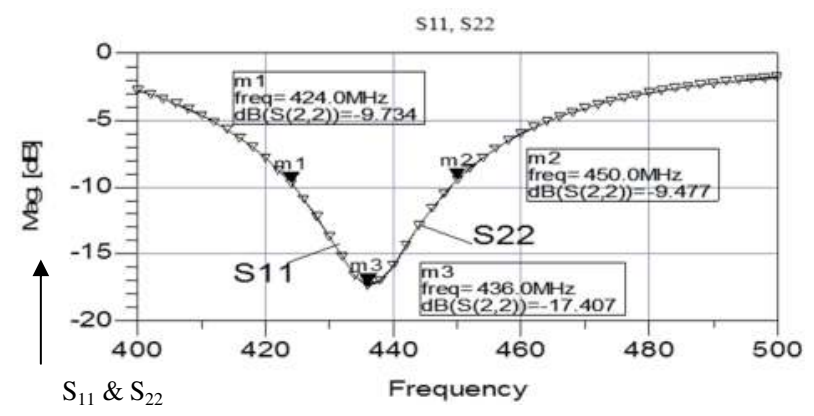

Figure 2. Computed $S_{11}$ and $S_{22}$ results

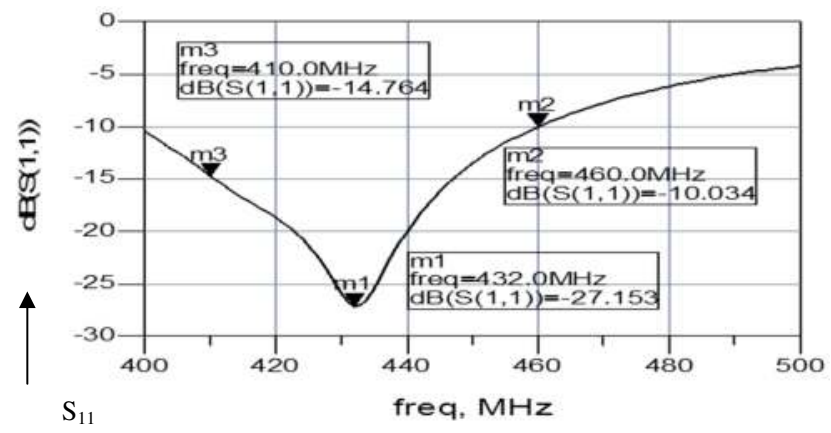

Figure 3. Measured $\mathrm{S}_{11}$ on human body

The phantom has a cylindrical shape with a $40 \mathrm{~cm}$ diameter and a length of $1.5 \mathrm{~m}$. The phantom contains a mix of $55 \%$ water $44 \%$ sugar and $1 \%$ salt. The antenna under test was placed on the phantom during the measurements of the antennas radiation characteristics. $S_{11}$ and $S_{12}$ parameters were measured directly on human body by using a network analyzer. The measured results were compared to a known reference antenna.

\section{New loop antenna with ground plane}

A new loop antenna with ground plane has been designed on Kapton substrates with thickness of $0.25 \mathrm{~mm}$ and $0.4 \mathrm{~mm}$. The antenna without ground plane is shown in Figure 8 . The loop antenna VSWR without the tuning capacitor was 4:1. This loop antenna may be tuned by adding a capacitor or varactor as shown in Figure 8. Tuning the antenna allow us to work in a wider bandwidth. Figure 9 presents the loop antenna computed $S_{11}$ on human body. There is good agreement between measured and computed $S_{11}$. The computed radiation pattern is shown in Fig 10. 


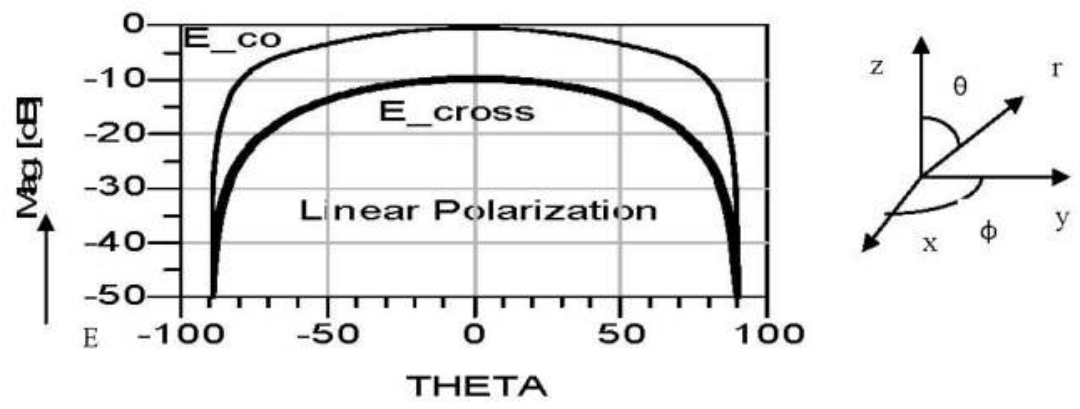

Figure 4. Antenna Radiation patterns

Table I compares the electrical performance of a loop antenna with ground plane with a loop antenna without ground plane. Tuning the antenna allow us to work in a wider bandwidth. Figure 9 presents the loop antenna computed S11on human body.

There is good agreement between measured and computed $S_{11}$. The computed radiation pattern is shown in Fig 10. Table I compares the electrical performance of a loop antenna with ground plane with a loop antenna without ground plane. There is a good agreement between measured and computed results of antenna parameters on human body. The results presented in Table I indicates that the loop antenna with ground plane is matched to the human body environment, without the tuning capacitor, better than the loop antenna without ground plane. The computed 3D radiation pattern is shown in Fig 11.

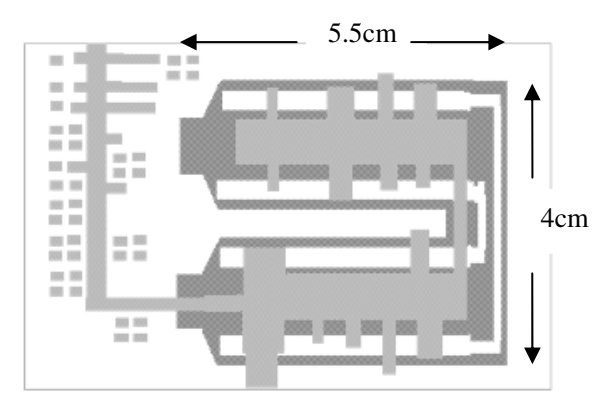

Figure 5. Folded dual polarized antenna, $7 \times 5 \times 0.16 \mathrm{~cm}$. 


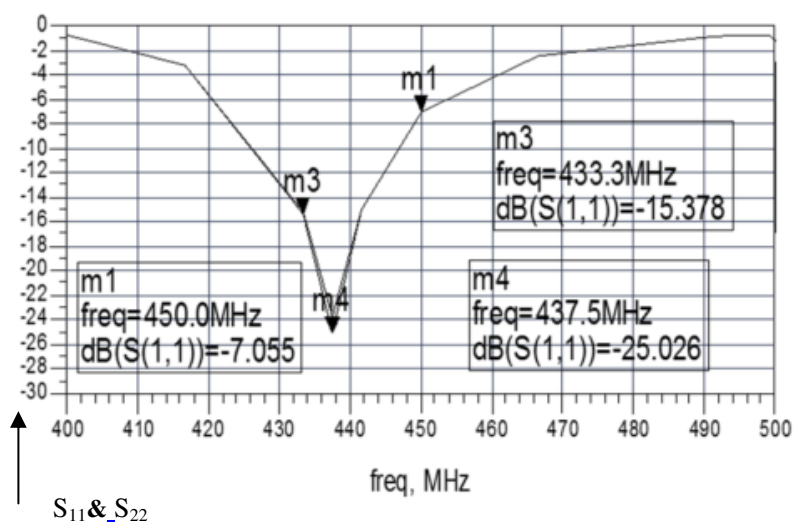

Figure 6. Folded antenna Computed $S_{11}$ and $S_{22}$ results

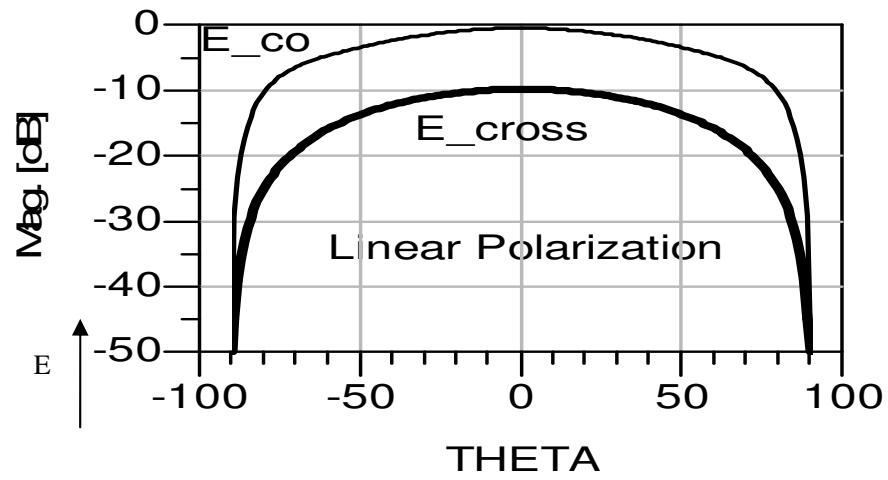

Figure 7. Folded antenna Radiation patterns 


\begin{tabular}{cccc}
\hline Antenna with no tuning capacitor & Beam width 3dB & Gain dBi & VSWR \\
\hline Loop no GND & $100^{\circ}$ & 0 & $4: 1$ \\
\hline Loop with GND & $100^{\circ}$ & 0 & $2: 1$ \\
\hline
\end{tabular}

Table 1. Comparison of Loop Antennas

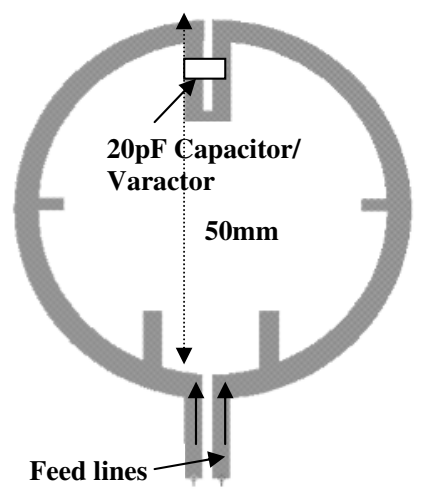

Figure 8. Tunable loop antenna without ground plane

The computed 3D radiation pattern and the coordinate used in this chapter are shown in Fig 11. Computed $S_{11}$ of the Loop Antenna with a tuning capacitor is given in Figure 12.

\section{Antenna S11 variation as function of distance from body}

The Antennas input impedance variation as function of distance from the body had been computed by employing ADS software. The analyzed structure is presented in Figure 14. The patient body thickness was varied from $15 \mathrm{~mm}$ to $300 \mathrm{~mm}$. The dielectric constant of the body was varied from 40 to 50 . The antenna was placed inside a belt with thickness between 2 to $4 \mathrm{~mm}$ with dielectric constant from 2 to 4 . The air layer between the belt and the patient shirt may vary from $0 \mathrm{~mm}$ to $8 \mathrm{~mm}$. The shirt thickness was varied from $0.5 \mathrm{~mm}$ to $1 \mathrm{~mm}$. The dielectric constant of the shirt was varied from 2 to 4 . Properties of human body tissues are listed in Table II see [8]. These properties were employed in the antenna design. Figure 15 presents $S_{11}$ results (of the antenna shown in Figure 1) for different belt thickness, shirt thickness and air spacing between the antennas and human body. 


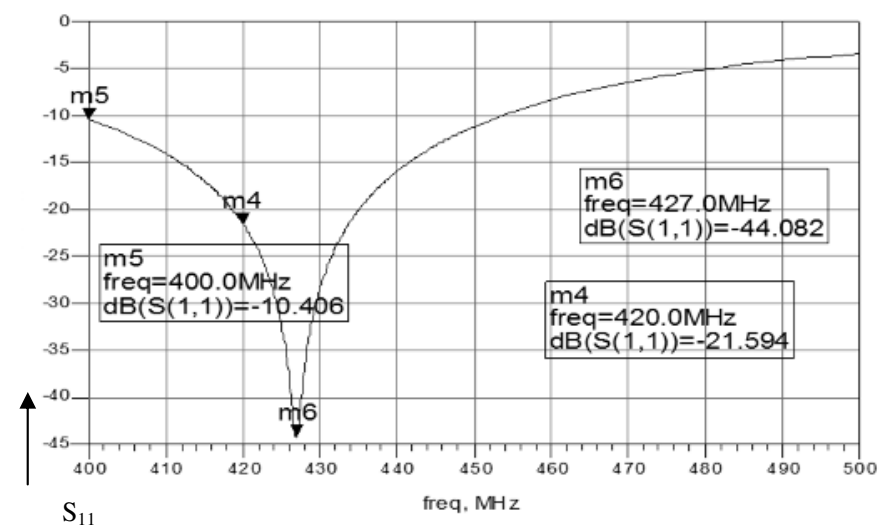

Figure 9. Computed $\mathrm{S}_{11}$ of new Loop Antenna

\section{Linear Polarization}

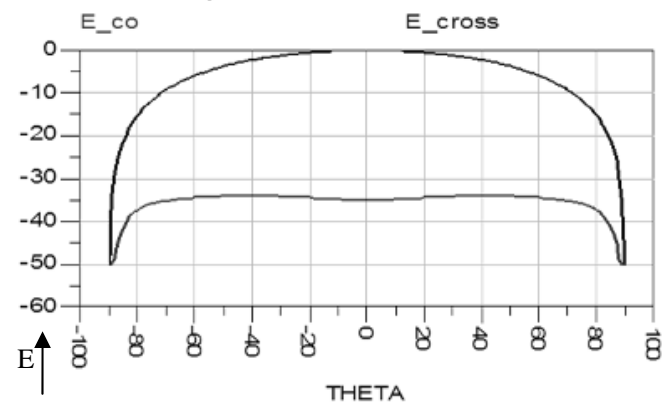

Figure 10. New Loop Antenna Radiation pattern on human body
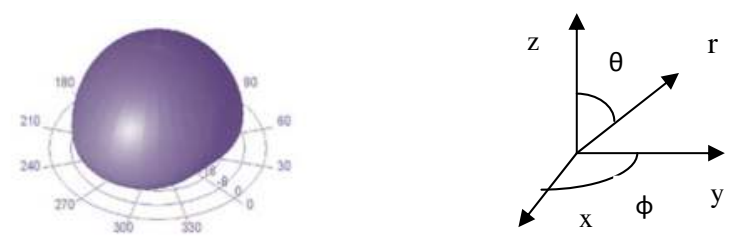

Figure 11. New Loop Antenna 3D Radiation pattern 


\begin{tabular}{cccc}
\hline Tissue & Property & $434 \mathrm{MHz}$ & $600 \mathrm{MHz}$ \\
\hline \multirow{2}{*}{ Skin } & $\sigma$ & 0.57 & 0.6 \\
& $\varepsilon$ & 41.6 & 40.43 \\
\hline Stomach & $\sigma$ & 0.67 & 0.73 \\
& $\varepsilon$ & 42.9 & 41.41 \\
\hline Colon, Muscle & $\sigma$ & 0.98 & 1.06 \\
& $\varepsilon$ & 63.6 & 61.9 \\
\hline & $\sigma$ & 0.27 & 0.27 \\
\hline
\end{tabular}

Table 2. Properties of human body tissues

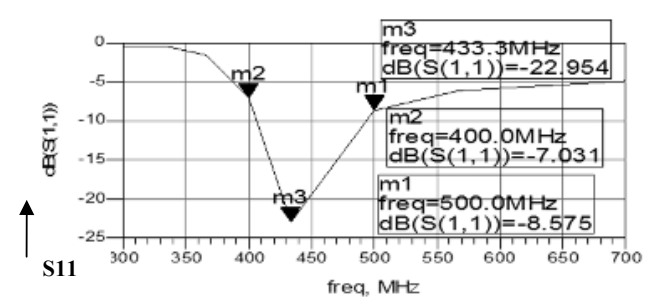

Figure 12. Computed $S_{11}$ of Loop Antenna, without ground plane, with a tuning capacitor

\section{Linear Polarization}

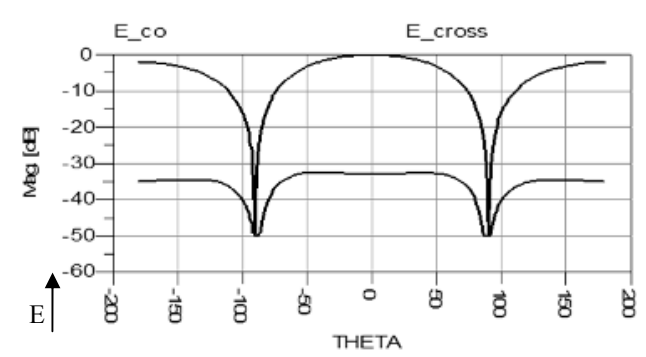

Figure 13. Radiation pattern of Loop Antenna without ground on human body

One may conclude from results shown in Figure 15 that the antenna has V.S.W.R better than 2.5:1 for air spacing up to $8 \mathrm{~mm}$ between the antennas and patient body. For frequencies ranging from 415MHz to $445 \mathrm{MHz}$ the antenna has V.S.W.R better than 2:1 when there is no air spacing between 
the antenna and the patient body. Results shown in Figure 16 indicates that the folded antenna (the antenna shown in Figure 5) has V.S.W.R better than 2.0:1 for air spacing up to $5 \mathrm{~mm}$ between the antennas and patient body. Figure 16 presents $S_{11}$ results of the folded antenna results for different position relative to the human body. Explanation of Figure 16 is given in Table 3 . If the air spacing between the sensors and the human body is increased from $0 \mathrm{~mm}$ to $5 \mathrm{~mm}$ the antenna resonant frequency is shifted by $5 \%$. The loop antenna with ground plane has V.S.W.R better than 2.0:1 for air spacing up to $5 \mathrm{~mm}$ between the antennas and patient body.

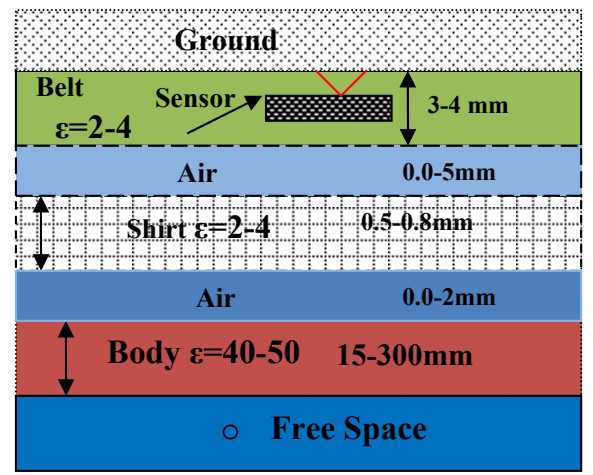

Figure 14. Analyzed structure for Impedance calculations

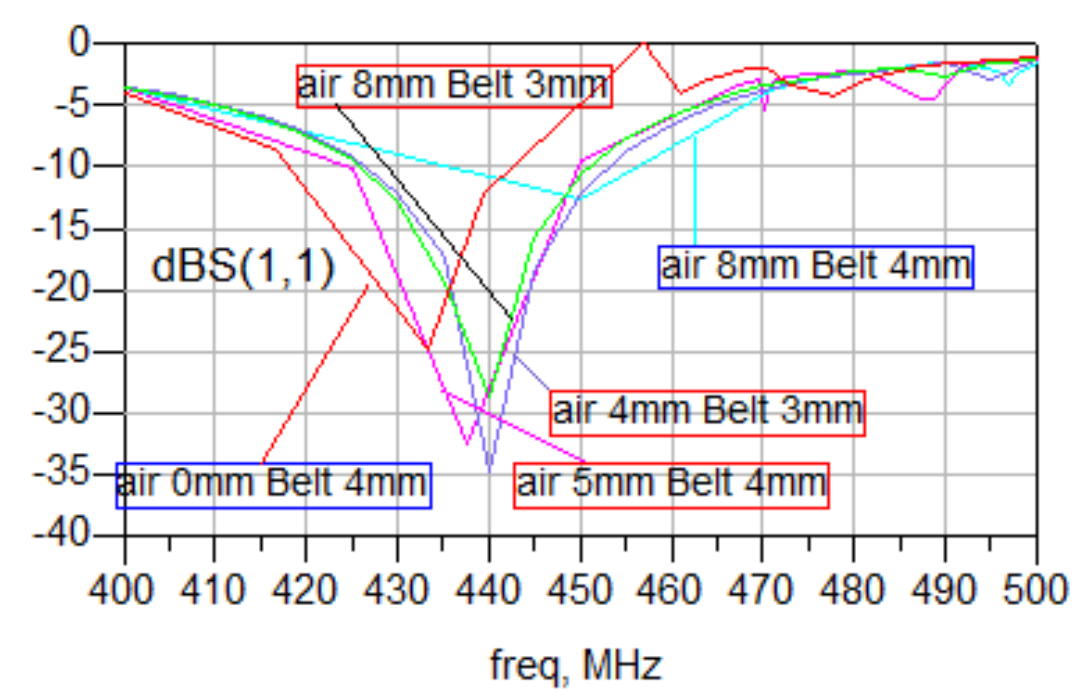

Figure 15. $\mathrm{S}_{11}$ results for different antenna positions relative to the human body 
If the air spacing between the sensors and the human body is increased from $0 \mathrm{~mm}$ to $5 \mathrm{~mm}$ the computed antenna resonant frequency is shifted by $2 \%$. However, if the air spacing between the sensors and the human body is increased up to $5 \mathrm{~mm}$ the measured loop antenna resonant frequency is shifted by 5\%. Explanation of Figure 17 is given in Table 4.

\begin{tabular}{ll}
\hline Plot colure & Sensor position \\
\hline Red & Shirt thickness $0.5 \mathrm{~mm}$ \\
\hline Blue & Shirt thickness $1 \mathrm{~mm}$ \\
\hline Pink & Air spacing $2 \mathrm{~mm}$ \\
\hline Green & Air spacing $4 \mathrm{~mm}$ \\
\hline Sky & Air spacing $1 \mathrm{~mm}$ \\
\hline Purple & Air spacing $5 \mathrm{~mm}$ \\
\hline
\end{tabular}

Table 3. Explanation of Figure 16

\section{Wearable antenna}

An application of the proposed antenna is shown in Figure 18. Three to four folded dipole or loop antennas may be assembled in a belt and attached to the patient stomach. The cable from each antenna is connected to a recorder. The received signal is routed to a switching matrix. The signal with the highest level is selected during the medical test. The antennas receive a signal that is transmitted from various positions in the human body. Folded antennas may be also attached on the patient back in order to improve the level of the received signal from different locations in the human body. Figure 19 and Figure 20 show various antenna locations on the back and front of the human body for different medical applications.

\begin{tabular}{ll}
\hline Plot colure & Sensor position \\
\hline Red & Body $15 \mathrm{~mm}$ air spacing $0 \mathrm{~mm}$ \\
\hline Blue & Air spacing $5 \mathrm{~mm}$ Body $15 \mathrm{~mm}$ \\
\hline Pink & Body $40 \mathrm{~mm}$ air spacing $0 \mathrm{~mm}$ \\
\hline Green & Body $30 \mathrm{~mm}$ air spacing $0 \mathrm{~mm}$ \\
\hline Sky & Body $15 \mathrm{~mm}$ Air spacing $2 \mathrm{~mm}$ \\
\hline Purple & Body $15 \mathrm{~mm}$ Air spacing $4 \mathrm{~mm}$ \\
\hline
\end{tabular}

Table 4. Explanation of Figure 17

transmitting and receiving antennas is less than $2 \mathrm{D}^{2} / \lambda$. D is the largest dimension of the radiator. In these applications the amplitude of the electromagnetic field close to the antenna may be quite 
powerful, but because of rapid fall-off with distance, the antenna do not radiate energy to infinite distances, but instead the radiated power remain trapped in the region near to the antenna. Thus, the near-fields only transfer energy to close distances from the receivers. The receiving and transmitting antennas are magnetically coupled. Change in current flow through one wire induces a voltage across the ends of the other wire through electromagnetic induction. The amount of inductive coupling between two conductors is measured by their mutual inductance. In these applications we have to refer to the near field and not to the far field radiation.

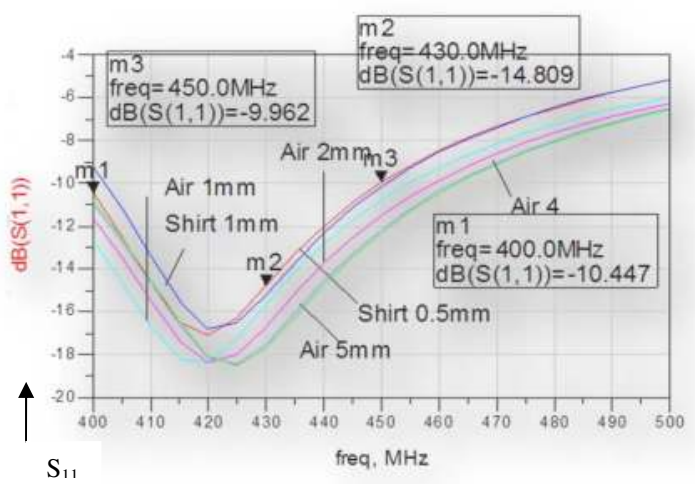

Figure 16. Folded antenna $S_{11}$ results for different antenna position relative to the human body

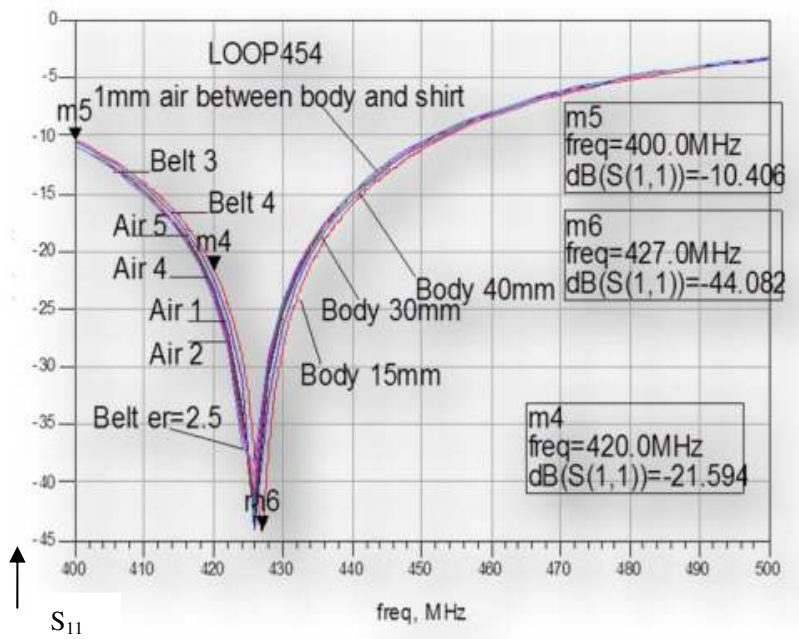

Figure 17. Loop antenna $S_{11}$ results for different antenna position relative to the human body 


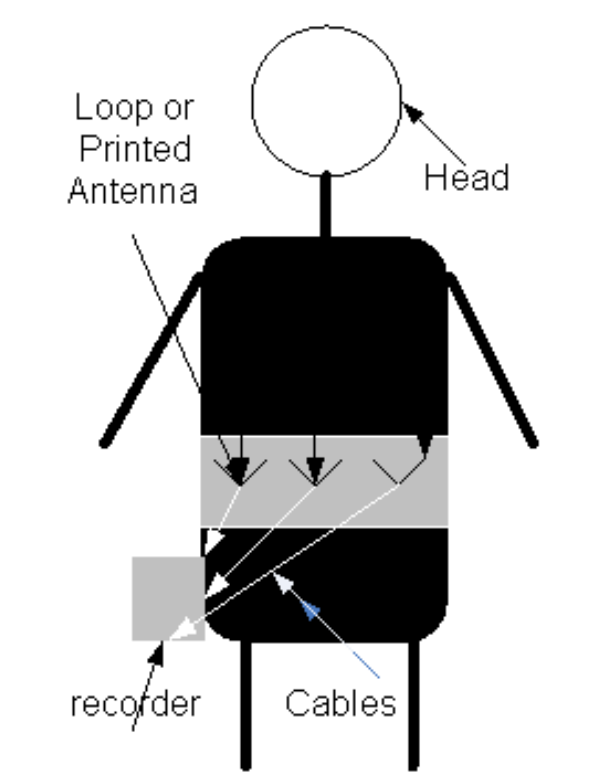

Figure 18. Printed Wearable antenna

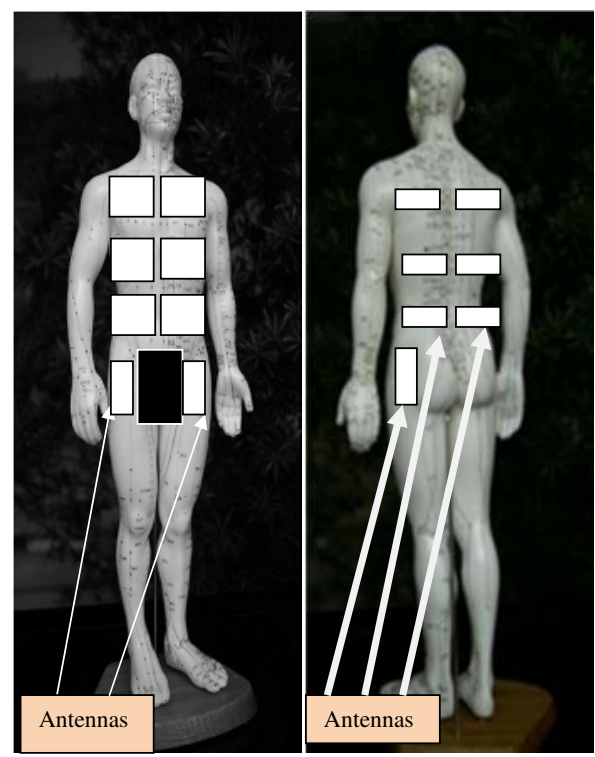

Figure 19. Printed Patch Antenna locations for various medical applications 
In Figure 20 and 21 several microstrip antennas for medical applications at $434 \mathrm{MHz}$ are shown. The Backside of the antennas is presented in Figure 20.b. The diameter of the loop antenna presented in Figure 21 is $50 \mathrm{~mm}$. The dimensions of the folded dipole antenna are $7 \times 6 \times 0.16 \mathrm{~cm}$. The dimensions of the compact folded dipole presented in Figure 21 are 5x5x0.5cm.
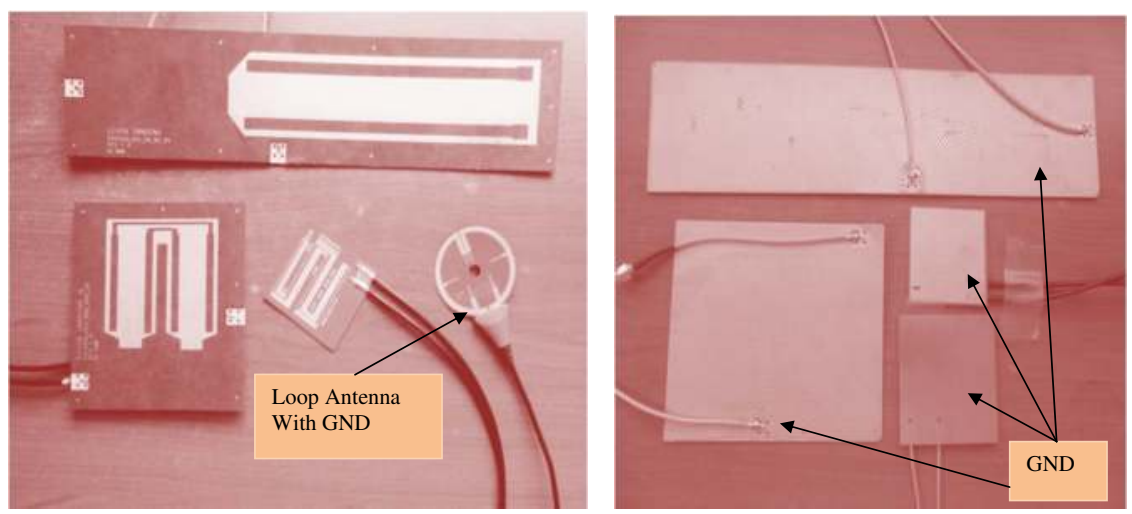

Figure 20. a. Microstrip Antennas for medical Applications b. Backside of the antennas6. Compact dual polarized printed antenna

A new compact microstrip loaded dipole antennas has been designed. The antenna consists of two layers. The first layer consistsof FR4 $0.25 \mathrm{~mm}$ dielectric substrate. The second layer consists of Kapton $0.25 \mathrm{~mm}$ dielectric substrate. The substrate thickness determines the antenna bandwidth. However, with thinner substrate we may achieve better flexibility. The proposed antenna is dual polarized. The printed dipole and the slot antenna provide dual orthogonal polarizations. The dual polarized antenna is shown in Figure 22. The antenna dimensions are $5 \times 5 \times 0.05 \mathrm{~cm}$.

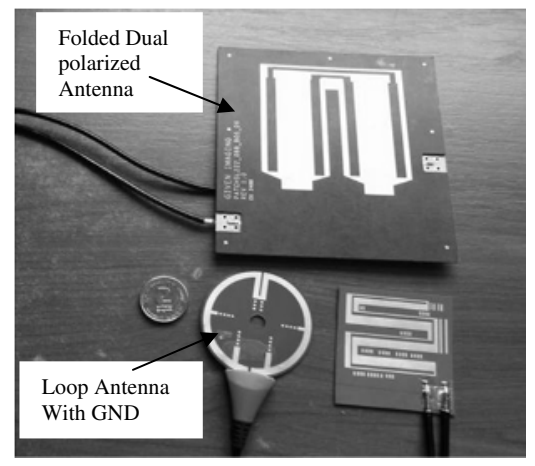

Figure 21. Microstrip Antennas for medical Applications 
The antenna may be attached to the patient shirt in the patient stomach or back zone. The antenna has been analyzed by using Agilent ADS software. There is a good agreement between measured and computed results. The antenna bandwidth is around $10 \%$ for VSWR better than $2: 1$. The antenna beam width is around $100^{\circ}$. The antenna gain is around $0 \mathrm{dBi}$. The computed $S_{11}$ parameters are presented in Figure 23. Figure 24 presents the antenna measured $S_{11}$ parameters. The antenna cross-polarized field strength may be adjusted by varying the slot feed location. The computed 3D radiation pattern of the antenna is shown in Figure 25. The computed radiation pattern is shown in Figure 26.

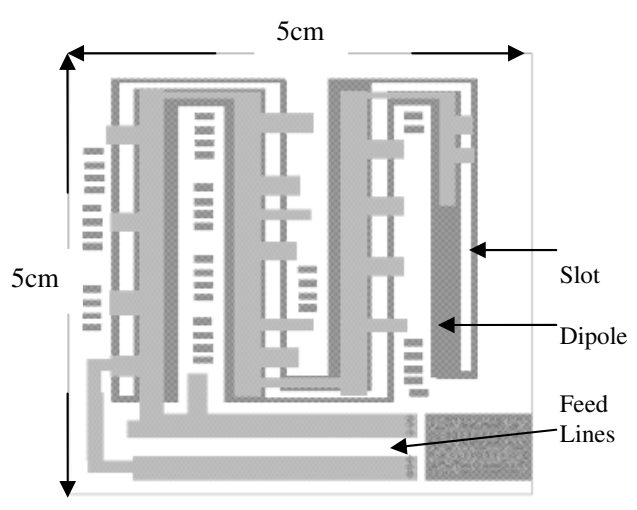

Figure 22. Printed Compact dual polarized antenna

\section{Helix antenna performance on human body}

In order to compare the variation of the new antenna input impedance as function of distance from the body to other antennas a helix antenna has been designed. A helix antenna with 9 turns is shown in figure 27. The backside of the circuit is copper under the microstrip matching stubs. However, in the helix antenna area there is no ground plane. The antenna has been designed to operate on human body. A matching microstrip line network has been designed on RO4003 substrate with $0.8 \mathrm{~mm}$ thickness. The helix antenna has VSWR better than 3:1 at the frequency range from $440 \mathrm{MHz}$ to $460 \mathrm{MHz}$. The antenna dimensions are $4 \times 4 \times 0.6 \mathrm{~cm}$. Figure 28 presents the measured $S_{11}$ parameters on human body. The computed $\mathrm{E}$ and $\mathrm{H}$ radiation plane of the helix antenna is shown in Figure 29. The helix antenna input impedance variation as function of distance from the body is very sensitive. If the air spacing between the helix antenna and the human body is increased from $0 \mathrm{~mm}$ to $2 \mathrm{~mm}$ the antenna resonant frequency is shifted by $5 \%$. 


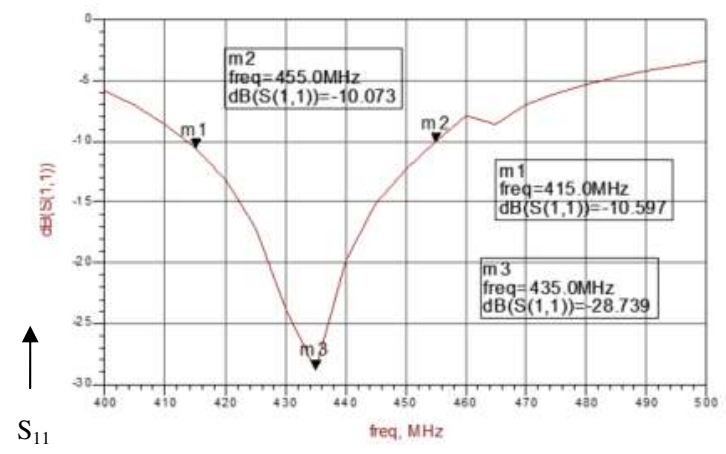

Figure 23. Computed $S_{11}$ results of compact antenna

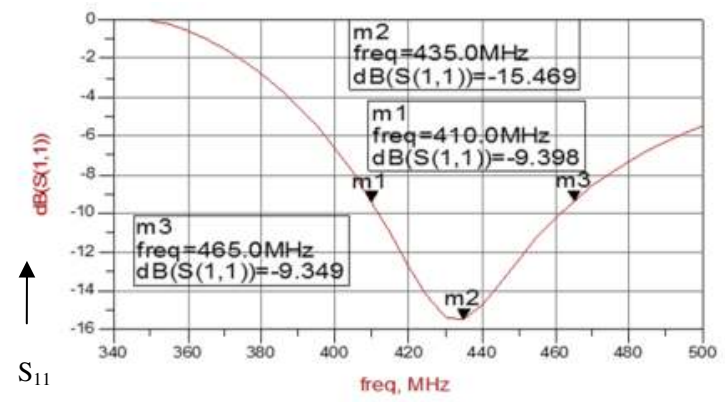

Figure 24. Measured $\mathrm{S}_{11}$ on human body

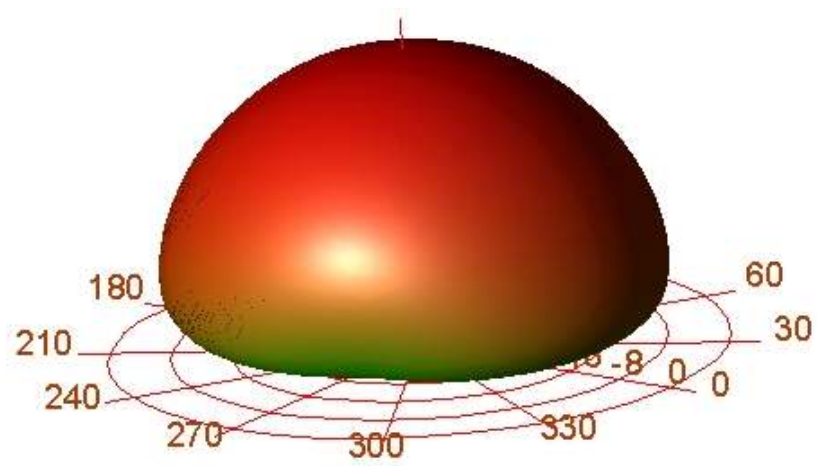

Figure 25. Compact Antenna 3D Radiation pattern 


\section{Linear Polarization}

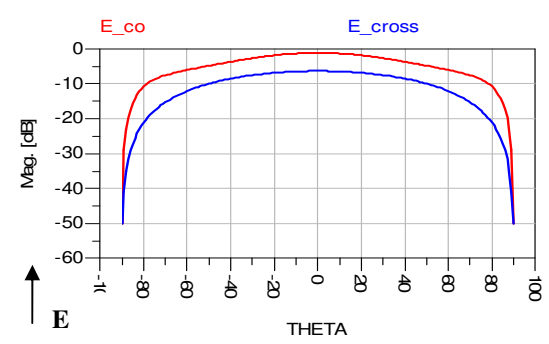

Figure 26. Antenna Radiation pattern

However, if the air spacing between the new dual polarized antenna and the human body is increased from $0 \mathrm{~mm}$ to $5 \mathrm{~mm}$ the antenna resonant frequency is shifted only by $5 \%$.

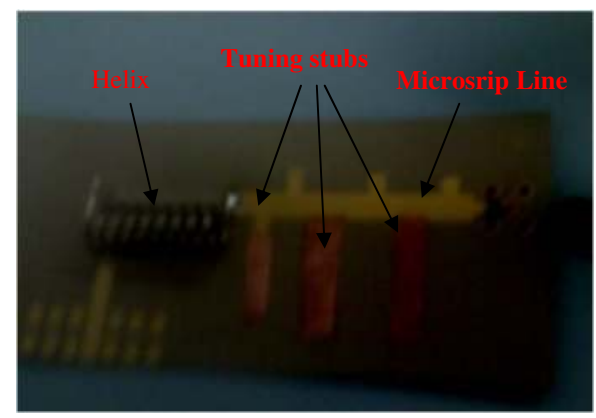

Figure 27. Helix Antenna for medical Applications

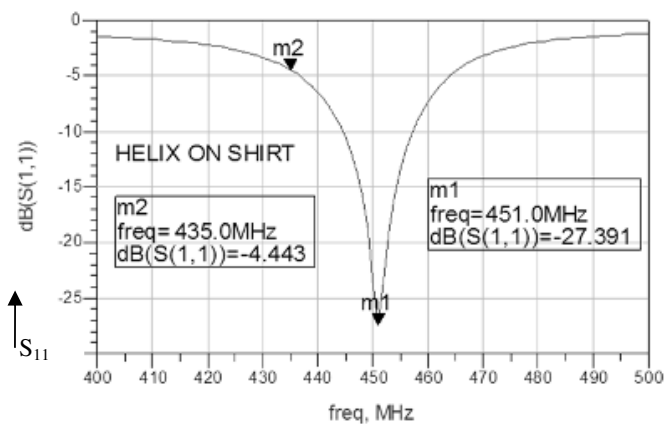

Figure 28. Measured $S_{11}$ on human body 

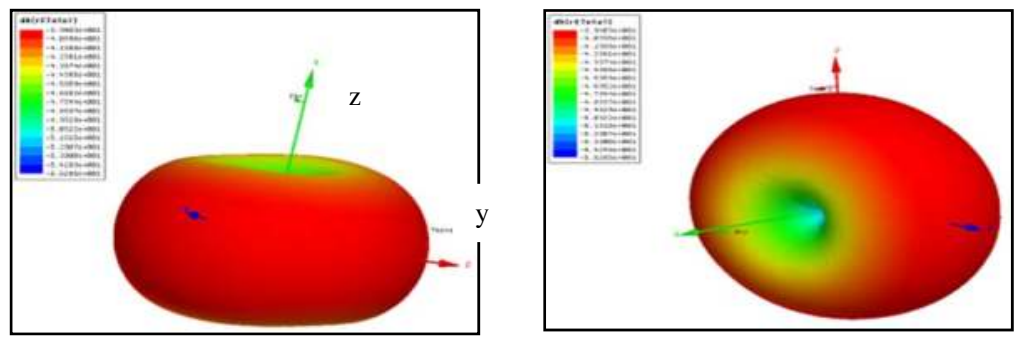

Figure 29. E and $\mathrm{H}$ plane radiation pattern of The Helix antenna

\section{Wearable tunable printed antennas for medical applications}

A new class of wideband tunable wearable microstrip antennas for medical applications is presented in this section. The antennas VSWR is better than 2:1at $434 \mathrm{MHz}+5 \%$. The antenna beam width is around $100^{\circ}$. The antennas gain is around 0 to $2 \mathrm{dBi}$. A voltage controlled varactor is used to control the antenna resonant frequency at different locations on the human body.

\subsection{Dually polarized tunable printed antenna}

A compact tunable microstrip dipole antenna has been designed to provide horizontal polarization. The antenna consists of two layers. The first layer consists of RO3035 $0.8 \mathrm{~mm}$ dielectric substrate. The second layer consists of RT-Duroid $58800.8 \mathrm{~mm}$ dielectric substrate. The substrate thickness affects the antenna band width. The printed slot antenna provides a vertical polarization. The printed dipole and the slot antenna provide dual orthogonal polarizations. The dimensions of the dual polarized antenna are $26 \times 6 \times 0.16 \mathrm{~cm}$. Also tunable compact folded dual polarized antennas have been designed. The dimensions of the compact antennas are $5 \times 5 \times 0.05 \mathrm{~cm}$. Varactors are connected to the antenna feed lines as shown in Figure 30. The voltage controlled varactors are used to control the antenna resonant frequency. The varactor bias voltage may be varied automatically to set the antenna resonant frequency at different locations on the human body. The antenna may be used as a wearable antenna on a human body. The antenna may be attached to the patient shirt in the patient stomach or back zone. The antenna has been analyzed by using Agilent ADS software. There is a good agreement between measured and computed results. The antenna bandwidth is around $10 \%$ for VSWR better than 2:1. The antenna beam width is around $100^{\circ}$. The antenna gain is around $2 \mathrm{dBi}$. 


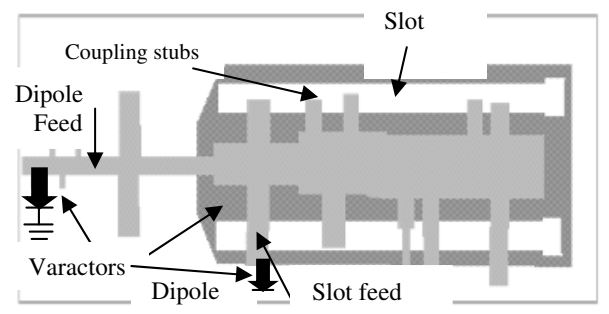

Figure 30. Dual polarized tunable antenna, $26 \times 6 \times 0.16 \mathrm{~cm}$.

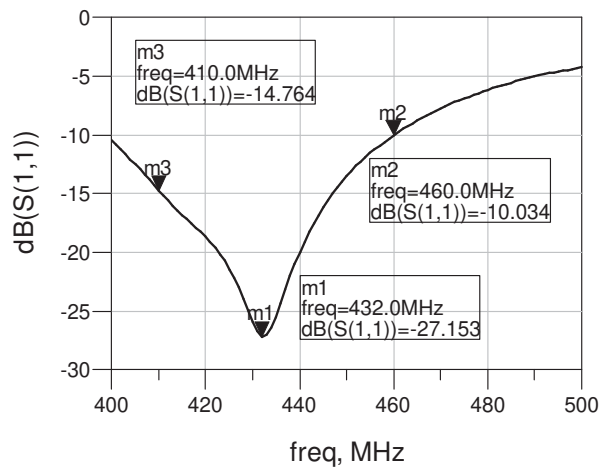

Figure 31. Measured $\mathrm{S}_{11}$ on human body

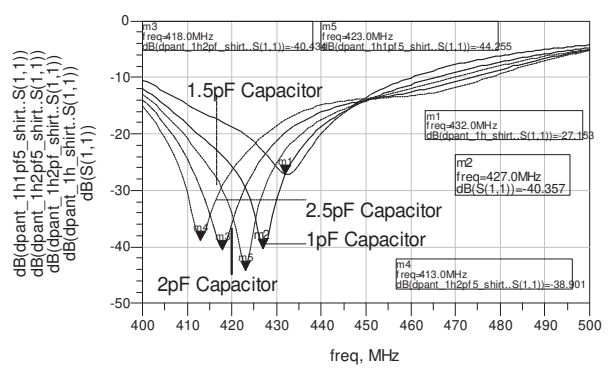

Figure 32. The Tunable $S_{11}$ parameter as function of varactor capacitance 
Figure 31 presents the antenna measured $S_{11}$ parameters without a varactor. Figure 32 presents the antenna $S_{11}$ parameters as function of different varactor capacitances. Figure 33 presents the tunable antenna resonant frequency as function of the varactor capacitance. The antenna resonant frequency varies around $5 \%$ for capacitances up to $2.5 \mathrm{pF}$. The antenna beam width is $100^{\circ}$. The antenna cross polarized field strength may be adjusted by varying the slot feed location.

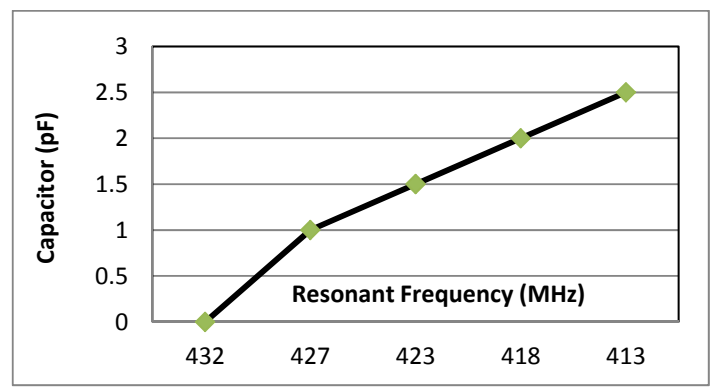

Figure 33. Resonant frequency as function of varactor capacitance

\subsection{Antenna S11 varitaion as function of distance from body}

The Antennas input impedance variation as function of distance from the body had been computed by employing ADS software. The analyzed structure is presented in Figure 14. Properties of human body tissues are listed in Table 2 see [8]. Figure 34 presents $S_{11}$ results for different belt and shirt thickness, and air spacing between the antennas and human body.

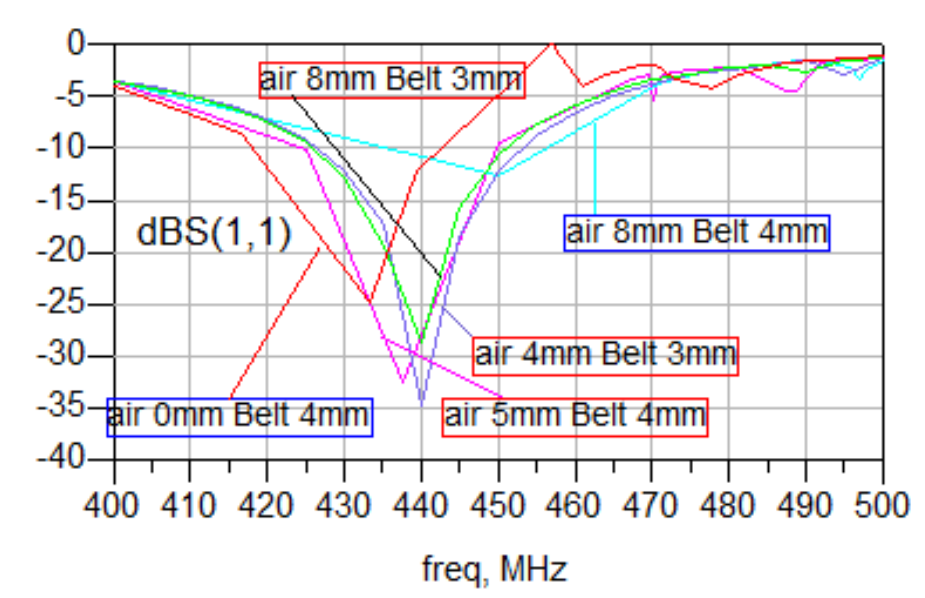

Figure 34. $\mathrm{S}_{11}$ results for different antenna positions 
If the air spacing between the sensors and the human body is increased from $0 \mathrm{~mm}$ to $5 \mathrm{~mm}$ the antenna resonant frequency is shifted by $5 \%$. There is good agreement between measured and calculated results. The voltage controlled varactor may be used to tune the antenna resonant frequency due to different antenna locations on a human body. Figure 35 presents several compact tunable Antennas for medical Applications. A voltage controlled varactor may be used also to tune the loop antenna resonant frequency at different antenna locations on the body.

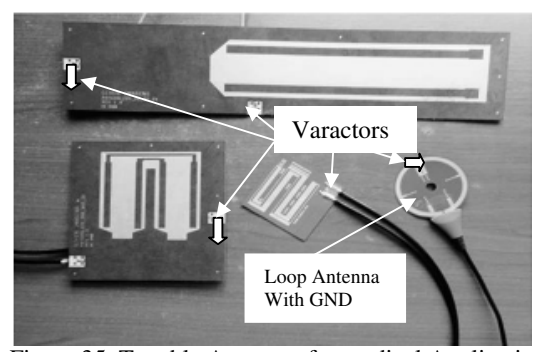

Figure 35. Tunable Antennas for medical Applications

\subsection{Varactors}

Tuning varactors are voltage variable capacitors designed to provide electronic tuning of microwave components. Varactors are manufactured on silicon and gallium arsenide substrates. Gallium arsenide varactors offer higher $Q$ and may be used at higher frequencies than silicon varactors. Hyperabrupt varactors provide nearly linear variation of frequency with applied control voltage. However abrupt varactors provide inverse fourth root frequency dependence. MACOM offers several gallium arsenide hyperabrupt varactors such as MA46 series. Figure 36 presents the C-V curves of varactors MA46505 to MA46506.

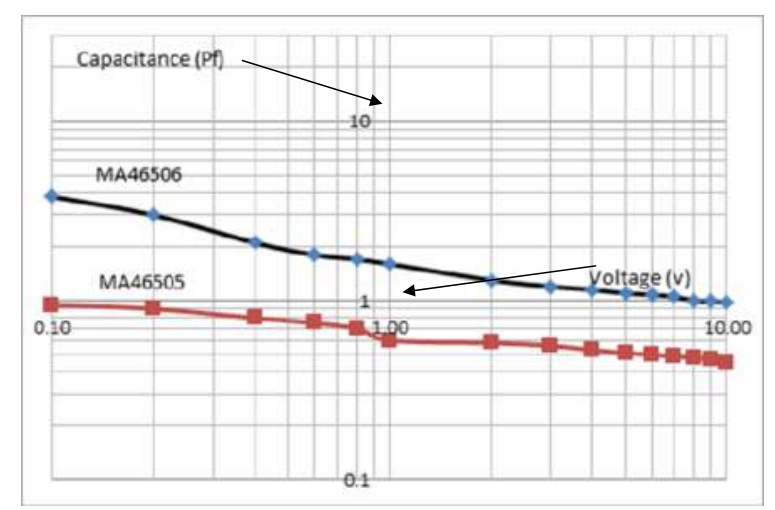

Figure 36. Varactor capacitance as function of bias voltage 
Figure 37 presents the C-V curves of varactors MA46H070 to MA46H074

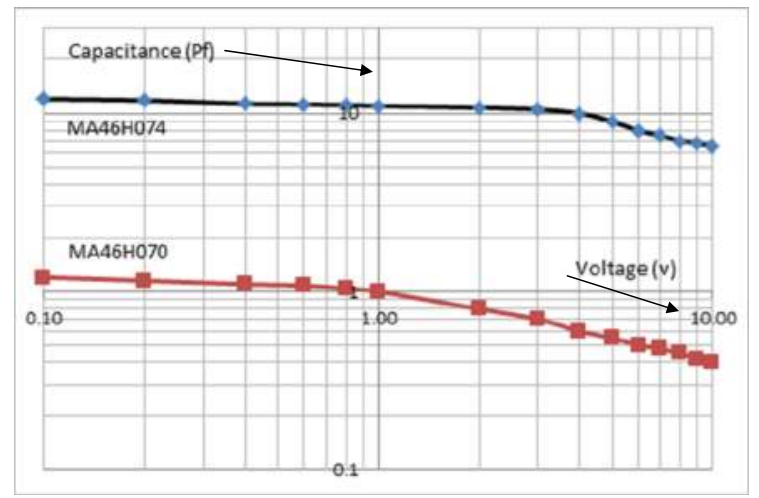

Figure 37. C-V curves of varactors MA46H070 to MA46H076

Figure 38 presents a compact tunable antenna with a varactor. Figure 39. presents measured $\mathrm{S}_{11}$ as function of varactor bias voltage. We may conclude that varactors may be used to compensate variations in the antenna resonant frequency at different locations on the human body.

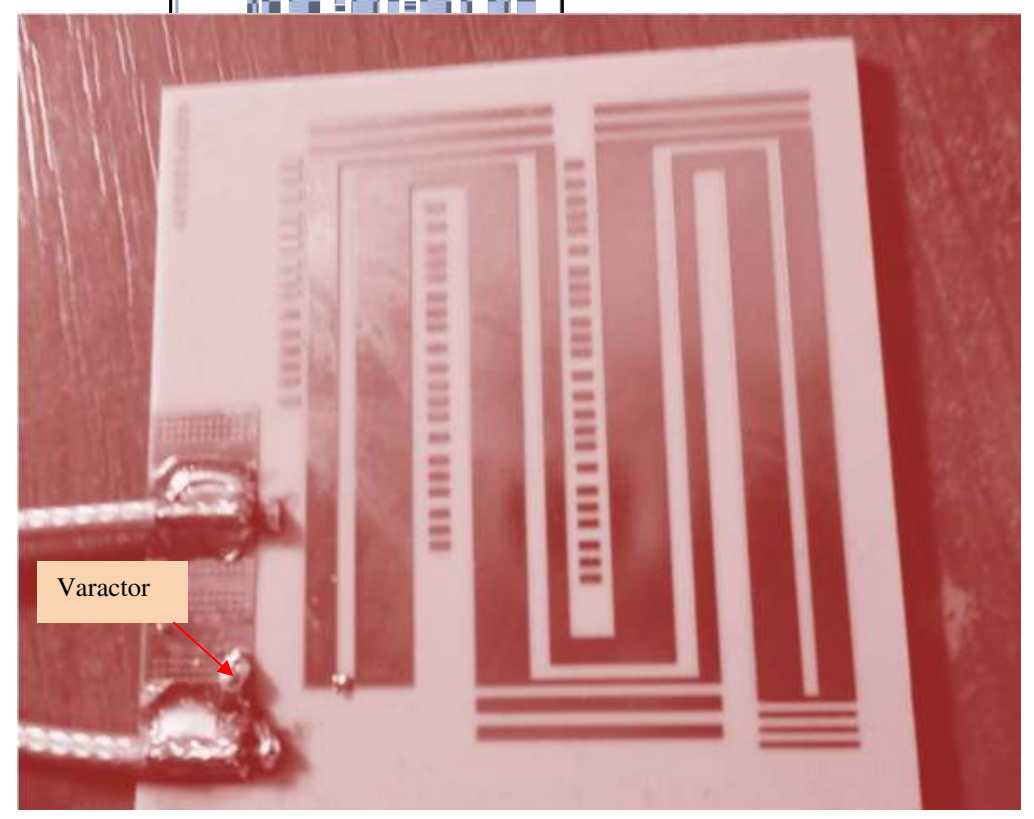

Figure 38. Tunable antenna with a varactor 


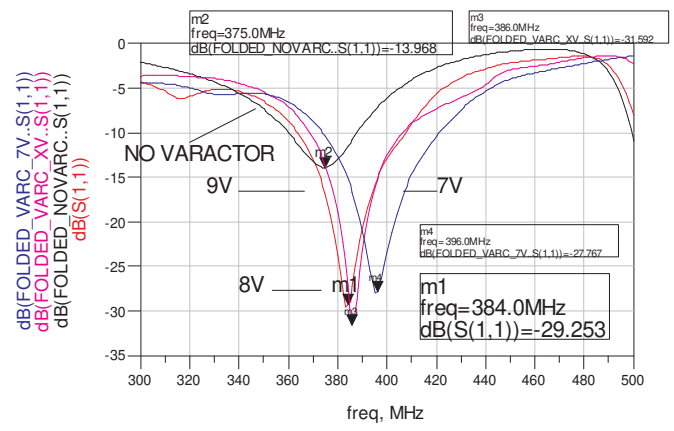

Figure 39. Measured $\mathrm{S}_{11}$ as function of varactor bias voltage

\section{Compact wearable RFID antennas}

RFID (Radio Frequency Identification) is an electronic method of exchanging data over radio frequency waves. There are three major components in RFID system: Transponder (Tag), Antenna and a Controller. The RFID tag, antenna and controller may be assembled on the same board. Microstrip antennas are widely presented in books and papers in the last decade [1-7]. However, compact wearable printed antennas are not widely used at $13.5 \mathrm{MHz}$ RIFD systems. HF tags work best at close range but are more effective at penetrating non-metal objects especially objects with high water content.

A new class of wideband compact printed and microstrip antennas for RFID applications is presented in this chapter.

RF transmission properties of human tissues have been investigated in several papers [8-9]. The effect of human body on the antenna performance is investigated in this chapter. The proposed antennas may be used as wearable antennas on persons or animals. The proposed antennas may be attached to cars, trucks, containers and other various objects.

\subsection{Dual polarized $13.5 \mathrm{MHz}$ compact printed antenna}

One of the most critical elements of any RFID system is the electrical performance of its antenna. The antenna is the main component for transferring energy from the transmitter to the passive RFID tags, receiving the transponder's replying signal and avoiding in-band interference from electrical noise and other nearby RFID components. Low profile compact printed antennas are crucial in the development of RIFD systems.

A new compact microstrip loaded dipole antennas has been designed at $13.5 \mathrm{MHz}$ to provide horizontal polarization. The antenna consists of two layers. The first layer consists of FR4 
$0.8 \mathrm{~mm}$ dielectric substrate. The second layer consists of Kapton $0.8 \mathrm{~mm}$ dielectric substrate. The substrate thickness determines the antenna bandwidth. A printed slot antenna provides a vertical polarization. The proposed antenna is dual polarized. The printed dipole and the slot antenna provide dual orthogonal polarizations. The dual polarized RFID antenna is shown in Figure 40. The antenna dimensions are $6.4 \times 6.4 \times 0.16 \mathrm{~cm}$. The antenna may be attached to the customer shirt in the customer stomach or back zone. The antenna has been analyzed by using Agilent ADS software.

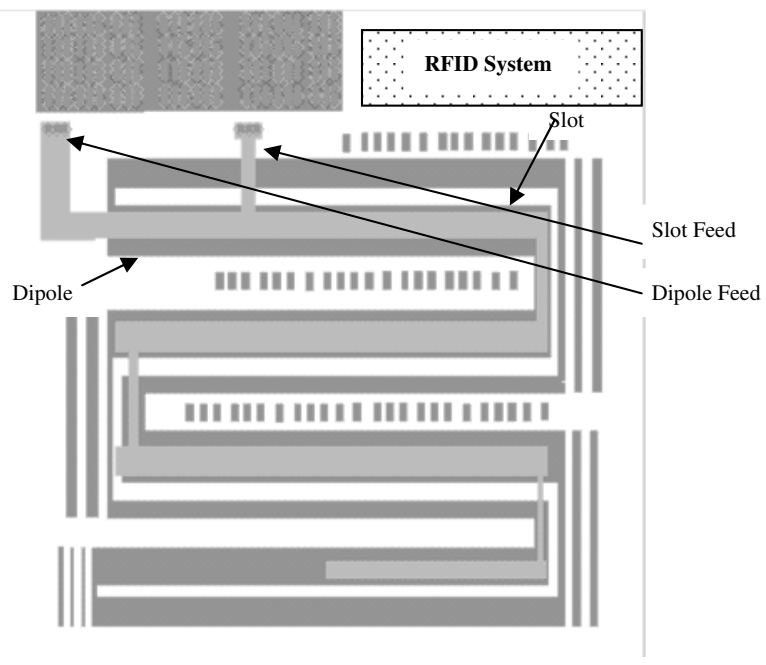

Figure 40. Printed Compact dual polarized antenna, $64 \times 64 \times 1.6 \mathrm{~mm}$

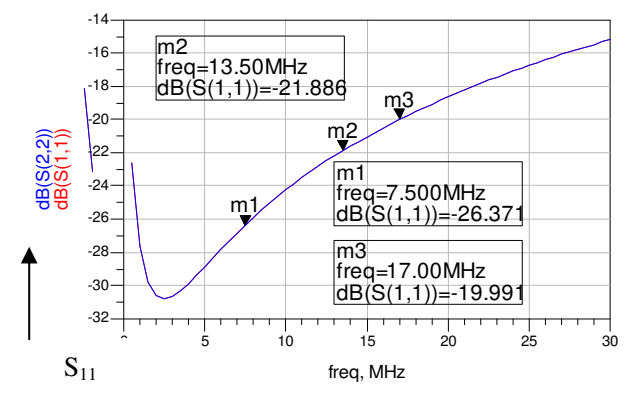

Figure 41. Computed $S_{11}$ results

The antenna S11parameter is better than $-21 \mathrm{~dB}$ at $13.5 \mathrm{MHz}$. The antenna gain is around $-10 \mathrm{dBi}$. The antenna beam width is around $160^{\circ}$. The computed $S_{11}$ parameters are presented in Figure 
41. There is a good agreement between measured and computed results. Figure 42 presents the antenna measured $S_{11}$ parameters. The antenna cross- polarized field strength may be adjusted by varying the slot feed location. The computed radiation pattern is shown in Figure 43. The computed 3D radiation pattern of the antenna is shown in Figure 44.

\subsection{Varying the antenna feed network}

Several designs with different feed network have been developed. A compact antenna with different feed network is shown in Figure 45. The antenna dimensions are $8.4 \times 6.4 \times 0.16 \mathrm{~cm}$. Figure 46 presents the antenna computed S11on human body. There is a good agreement between measured and computed results. The computed radiation pattern is shown in Fig 47. Table 5 compares the electrical performance of a loop antenna with the compact dual polarized antenna.

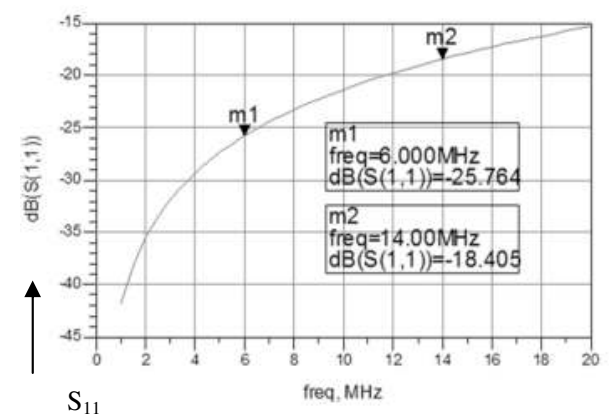

Figure 42. Measured $\mathrm{S}_{11}$ on human body

\section{Linear Polarization}

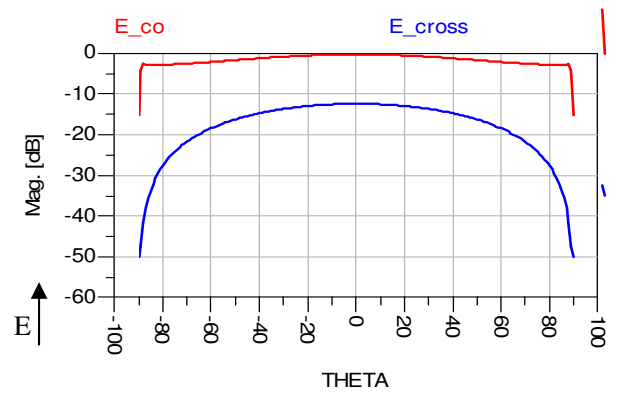

Figure 43. Antenna Radiation pattern 


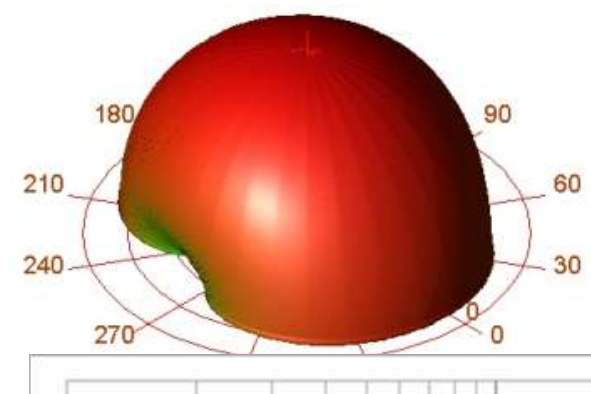

Figure 44. Antenna Radiation pattern

\subsection{RFID wearable loop antennas}

RFID loop antennas are widely used. Several RFID loop antennas are presented in [15]. RFID loop antennas have low efficiency and narrow bandwidth. As an example the measured impedance of a square four turn loop at $13.5 \mathrm{MHz}$ is

$0.47+\mathrm{j} 107.5 \Omega$. A matching network is used to match the antenna to $50 \Omega$. The matching network consists of a $56 \mathrm{pF}$ shunt capacitor, $1 \mathrm{k} \Omega$ shunt resistor and another $56 \mathrm{pF}$ capacitor. This matching network has narrow bandwidth.

A transmitting antenna is placed $20 \mathrm{~cm}$ from a square four turn loop antenna. $0 \mathrm{dBm} C W$ signal is applied to the transmitting antenna. The measured power level at the output of the loop antenna is $-50 \mathrm{dBm}$. A square four turn loop antenna has been designed at $13.5 \mathrm{MHz}$ by using Agilent ADS software.

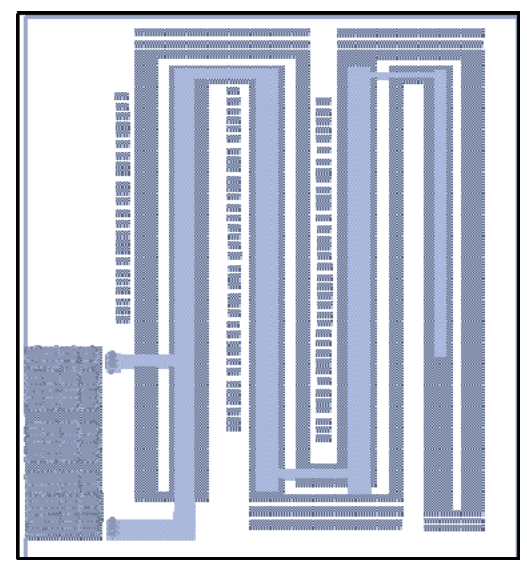

Figure 45. RFID printed antenna, $8.4 \times 6.4 \times 0.16 \mathrm{~cm}$. 


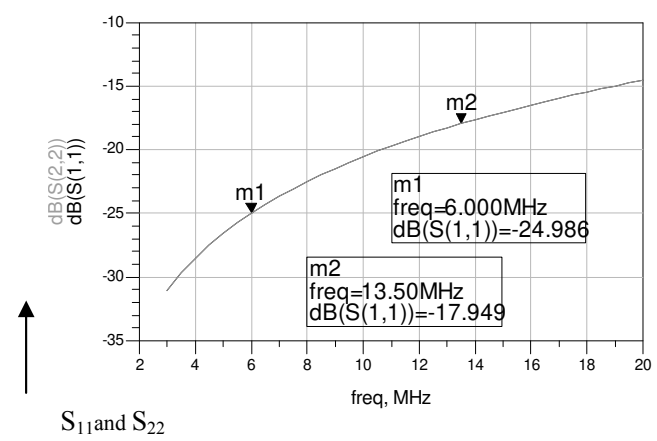

Figure 46. RFID Antenna Computed $S_{11}$ and $S_{22}$ results

The antenna is printed on a FR4 substrate. The antenna dimensions are $32 \times 52.4 \times 0.25 \mathrm{~mm}$. The antenna layout is shown in figure 48. S11 results of the printed loop antenna are shown in figure 49. The antenna $S_{11}$ parameter is better than $-9.5 \mathrm{~dB}$ without an external matching network. The computed radiation pattern is shown in Figure 50. The computed radiation pattern takes into account an infinite ground plane.

\begin{tabular}{cccc}
\hline Antenna & Beam width $^{\circ}$ 3dB & Gain dBi & VSWR \\
\hline Loop Antenna & 140 & -25 & $2: 1$ \\
\hline Microstrip Antenna & 160 & -10 & $1.2: 1$ \\
\hline
\end{tabular}

Table 5. Comparison of Loop Antenna and Microstrip antenna parameters

\section{Linear Polarization}

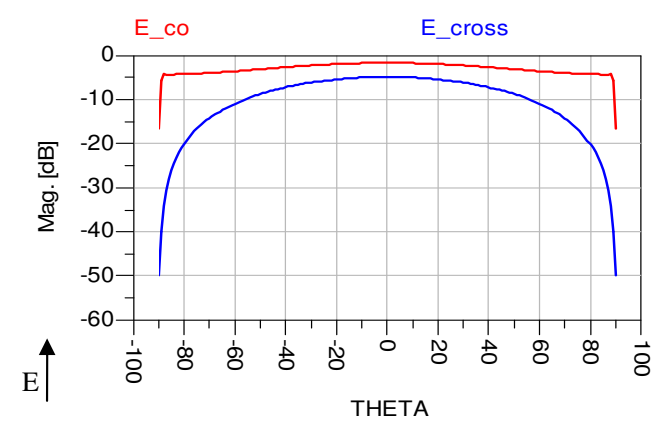

Figure 47. Compact Antenna, $8.4 \times 6.4 \times 0.16 \mathrm{~cm}$, Radiation pattern 


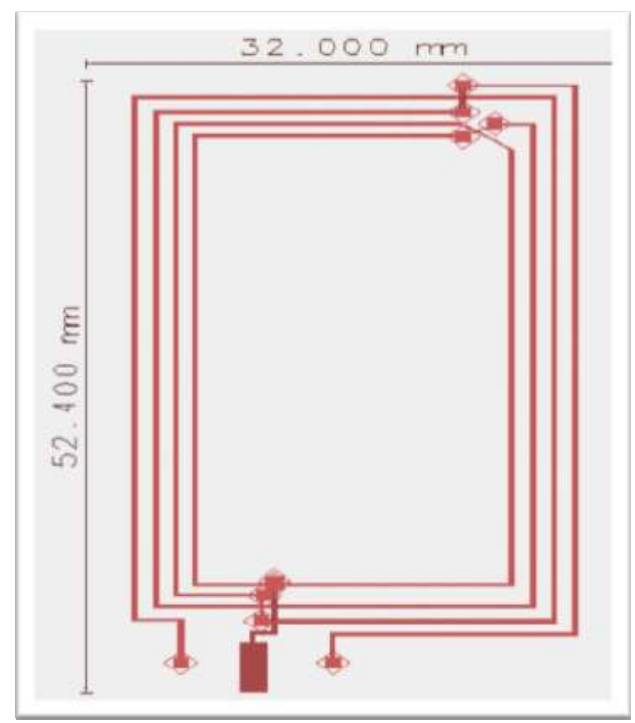

Figure 48. A square four turn loop antenna

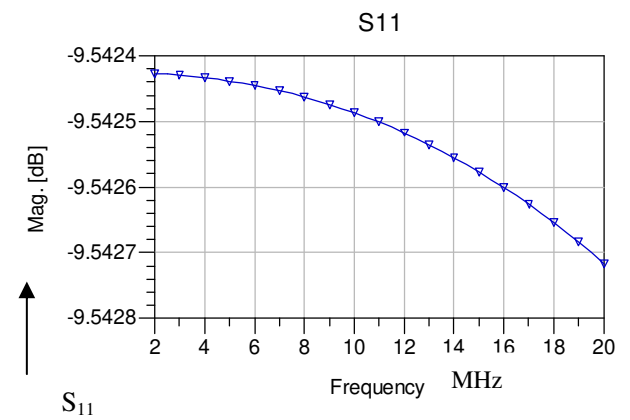

Figure 49. Loop Antenna Computed $S_{11}$ results

The Microstrip Antenna input impedance variation as function of distance from the body has been computed by employing ADS software. The analyzed structure is presented in Figure 14 Properties of human body tissues are listed in Table 2 see [8]. These properties were used in the antenna design. $S_{11}$ parameters for different human body thicknesses have been computed. We may note that the differences in the results for body thickness of $15 \mathrm{~mm}$ to $100 \mathrm{~mm}$ are negligible. $S_{11}$ parameters for different position relative to the human body have been computed. If the air spacing between theantenna and thehuman body is increased from $0 \mathrm{~mm}$ to $10 \mathrm{~mm}$ theantenna $\mathrm{S}_{11}$ parameters may change by less than $1 \%$. The VSWR is better than $1.5: 1$. 


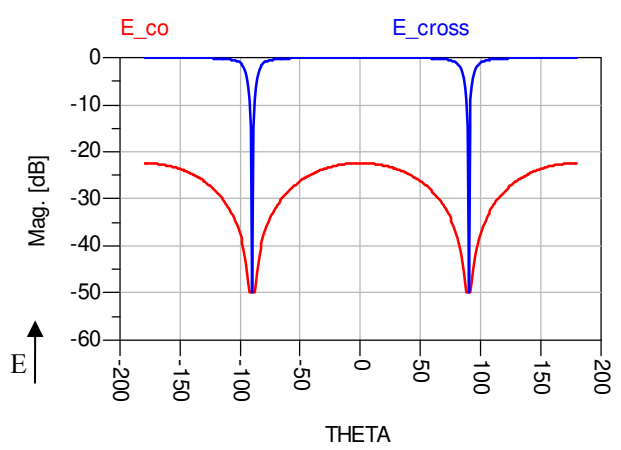

Figure 50. Loop Antenna Radiation patterns for an infinite ground plane

\subsection{Proposed antenna applications}

An application of the proposed antenna is shown in Figure 51. The RFID antennas may be assembled in a belt and attached to the customer stomach. The antennas may be employed as transmitting or as receiving antennas. The antennas may receive or transmit information to medical systems.

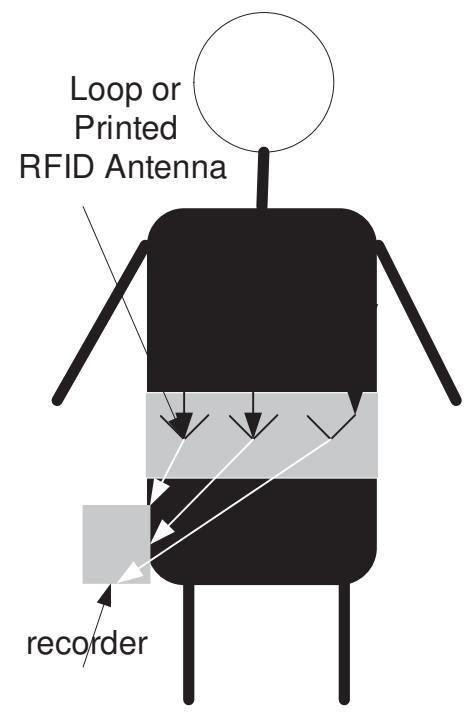

Figure 51. Wearable RFID antenna 
In RFID systems the distance between the transmitting and receiving antennas is less than $2 \mathrm{D}^{2} / \lambda$, where $\mathrm{D}$ is the largest dimension of the antenna. The receiving and transmitting antennas are magnetically coupled. In these applications we refer to the near field and not to the far field radiation pattern.

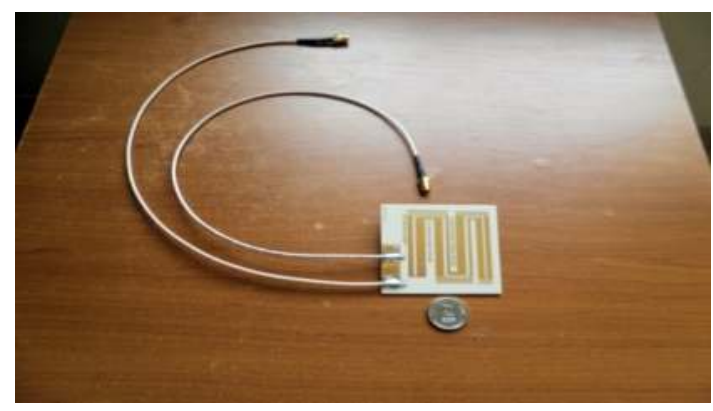

Figure 52. New Microstrip Antenna for RFID applications

Figure 52 and Figure 53 present compact printed antenna for RFID applications. The presented antennas may be assembled in a belt and attached to the patient stomach or back.

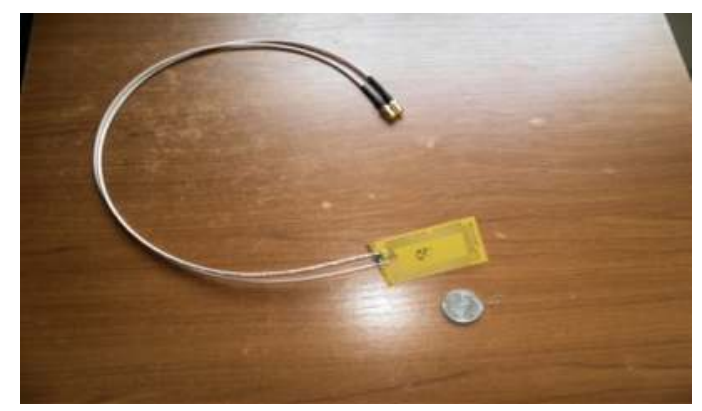

Figure 53. Loop Antenna for RFID applications

\section{Conclusions}

This chapter presents wideband microstrip antennas with high efficiency for medical applications. The antenna dimensions may vary from $26 \times 6 \times 0.16 \mathrm{~cm}$ to $5 \times 5 \times 0.05 \mathrm{~cm}$ according to the medical system specification. The antennas bandwidth is around $10 \%$ for VSWR better than 2:1. The antenna beam width is around $100^{\circ}$. The antennas gain varies from 0 to $4 \mathrm{dBi}$. The antenna S11 results for different belt thickness, shirt thickness and air spacing between the antennas and human body are presented in this chapter. If the air spacing between the new 
dual polarized antenna and the human body is increased from $0 \mathrm{~mm}$ to $5 \mathrm{~mm}$ the antenna resonant frequency is shifted by $5 \%$. However, if the air spacing between the helix antenna and the human body is increased only from $0 \mathrm{~mm}$ to $2 \mathrm{~mm}$ the antenna resonant frequency is shifted by $5 \%$. The effect of the antenna location on the human body should be considered in the antenna design process. The proposed antenna may be used in Medicare RF systems.

A wideband tunable microstrip antennas with high efficiency for medical applications has been presented in this chapter. The antenna dimensions may vary from $26 \times 6 \times 0.16 \mathrm{~cm}$ to $5 \times 5 \times 0.05 \mathrm{~cm}$ according to the medical system specification. The antennas bandwidth is around $10 \%$ for VSWR better than 2:1. The antenna beam width is around $100^{\circ}$. The antennas gain varies from 0 to $2 \mathrm{dBi}$. If the air spacing between the dual polarized antenna and the human body is increased from $0 \mathrm{~mm}$ to $5 \mathrm{~mm}$ the antenna resonant frequency is shifted by $5 \%$. A varactor is employed to compensate variations in the antenna resonant frequency at different locations on the human body.

This chapter presents also wideband compact printed antennas, Microstrip and Loop antennas, for RFID applications. The antenna beam width is around $160^{\circ}$. The antenna gain is around $-10 \mathrm{dBdBi}$. The proposed antennas may be used as wearable antennas on persons or animals. The proposed antennas may be attached to cars, trucks and other various objects. If the air spacing between the antenna and the human body is increased from $0 \mathrm{~mm}$ to $10 \mathrm{~mm}$ the antenna $S_{11}$ parameters may change by less than $1 \%$. The antenna VSWR is better than 1.5:1 for all tested environments.

\section{Author details}

Albert Sabban ${ }^{1,2,3^{*}}$

1 Ort Braude College, Karmiel, Israel

2 Tel Aviv University, Israel

3 Colorado University, Boulder, USA

\section{References}

[1] J.R. James, P.S Hall and C. Wood, “Microstrip Antenna Theory and Design”,1981.

[2] Sabban and K.C. Gupta, "Characterization of Radiation Loss from Microstrip Discontinuities Using a Multiport Network Modeling Approach", I.E.E.E Trans. on M.T.T, Vol. 39,No. 4,April 1991, pp. 705-712.

[3] Sabban," A New Wideband Stacked Microstrip Antenna", I.E.E.E Antenna and Propagation Symp., Houston, Texas, U.S.A, June 1983. 
[4] Sabban, E. Navon " A MM-Waves Microstrip Antenna Array", I.E.E.E Symposium, Tel-Aviv, March 1983.

[5] R. Kastner, E. Heyman, A. Sabban, "Spectral Domain Iterative Analysis of Single and Double-Layered Microstrip Antennas Using the Conjugate Gradient Algorithm", I.E.E.E Trans. on Antennas and Propagation, Vol. 36, No. 9, Sept. 1988, pp. 1204-1212.

[6] Sabban, "Wideband Microstrip Antenna Arrays", I.E.E.E Antenna and Propagation Symposium MELCOM, Tel-Aviv,1981.

[7] Sabban, "Microstrip Antenna Arrays", Microstrip Antennas, Nasimuddin Nasimuddin (Ed.), ISBN: 978-953-307-247-0, InTech, http://www.intechopen.com/articles/ show/title/microstrip-antenna-arrays , pp..361-384, 2011.

[8] Lawrence C. Chirwa*, Paul A. Hammond, Scott Roy, and David R. S. Cumming, "Electromagnetic Radiation from Ingested Sources in the Human Intestine between $150 \mathrm{MHz}$ and $1.2 \mathrm{GHz}$ ", IEEE Transaction on Biomedical eng., VOL. 50, NO. 4, April 2003, pp 484-492.

[9] D.Werber, A. Schwentner, E. M. Biebl, "Investigation of RF transmission properties of human tissues", Adv. Radio Sci., 4, 357-360, 2006.

[10] Gupta, B., Sankaralingam S., Dhar, S.,"Development of wearable and implantable antennas in the last decade", Microwave Symposium (MMS), 2010 Mediterranean 2010 , Page(s): $251-267$.

[11] Thalmann T., Popovic Z., Notaros B.M, Mosig, J.R.," Investigation and design of a multi-band wearable antenna", 3rd European Conference on Antennas and Propagation, EuCAP 2009. Pp. $462-465$.

[12] Salonen, P., Rahmat-Samii, Y., Kivikoski, M.," Wearable antennas in the vicinity of human body", IEEE Antennas and Propagation Society International Symposium, 2004. Vol.1 pp. $467-470$.

[13] Kellomaki T., Heikkinen J., Kivikoski, M., " Wearable antennas for FM reception", First European Conference on Antennas and Propagation, EuCAP 2006 , pp. 1-6.

[14] Sabban, "Wideband printed antennas for medical applications" APMC 2009 Conference, Singapore, 12/2009.

[15] Youbok Lee, "Antenna Circuit Design for RFID Applications", Microchip Technology Inc., Microchip AN 710c.

[16] ADS software, Agilent http://www.home.agilent.com/agilent/product.jspx? cc=IL\&lc=eng\&ckey=1297113\&nid=-34346.0.00\&id=1297113 
